\title{
IMPLEMENTASI ALGORITMA FP-GROWTH DAN APRIORI UNTUK PERSEDIAAN PRODUK
}

\author{
Dewi Anisa Istiqomah¹, Yuli Astuti², Siti Nurjanah ${ }^{3}$ \\ 1,2,3 Manajemen Informatika, Fakultas Ilmu Komputer, Universitas Amikom Yogyakarta \\ 1dewianisaist@amikom.ac.id, ${ }^{2}$ yuli@amikom.ac.id, ${ }^{3}$ siti.9156@student.amikom.ac.id
}

\begin{abstract}
Abstrak
Persediaan produk merupakan hal yang penting dalam mengelola bisnis, khususnya bisnis retail. Persediaan produk menjadi perhatian Toko Emyra Bedding untuk memaksimalkan pelayanannya. Persediaan produk pada Toko Emyra Bedding belum dikelola dengan baik, sehingga timbul beberapa permasalahan. Apabila salah satu produk yang dipesan tidak tersedia, maka permintaan pelanggan akan suatu produk menjadi terhambat. Selain itu, data transaksi penjualan terus menumpuk dalam jumlah besar setiap harinya dan hanya disimpan menjadi data yang belum diketahui manfaatnya. Penelitian ini bertujuan untuk mengetahui keterkaitan produk dengan algoritma Apriori dan FP-Growth menggunakan aplikasi RapidMiner. Dengan hal tersebut, diharapkan dapat menjadi solusi dalam kelola persediaan produk. Tahapan penelitian yaitu pengumpulan data, data preprocessing, pemodelan menggunakan algoritma Apriori dan FP-Growth, dan evaluasi. Penelitian ini menggunakan 150 data transaksi dan 17 produk. Hasil penelitian menunjukkan kedua algoritma dapat digunakan untuk menentukan aturan asosiasi guna mengetahui keterkaitan produk pada Toko Emyra Bedding. Aturan asosiasi yang dihasilkan oleh algoritma Apriori juga dihasilkan oleh algoritma FP-Growth. Algoritma Apriori menghasilkan 2 aturan asosiasi dan algoritma FP-Growth menghasilkan 10 aturan asosiasi dengan minimum support 0,05 dan minimum confidence 0,7. Berdasarkan pola hubungan yang dihasilkan, implementasi algoritma FP-Growth dan Apriori dapat membantu Toko Emyra Bedding untuk memantau stok barang yang sering dibeli oleh pelanggan sehingga tidak akan terjadi kelangkaan pasokan.
\end{abstract}

Kata kunci : Apriori, FP-Growth, aturan asosiasi, RapidMiner, persediaan produk

\section{Pendahuluan}

Persediaan produk merupakan hal yang penting dalam mengelola bisnis, khususnya bisnis retail. Persediaan produk dapat memengaruhi tingkat kepuasan pelanggan dan citra suatu toko. Pelanggan merasa puas jika produk yang dibutuhkan tersedia. Namun, jika pelanggan tidak mendapatkan produk yang dibutuhkan karena kekurangan stok, hal ini terjadi berulang kali, maka akan berdampak pada memburuknya citra toko. Persediaan produk menjadi perhatian Toko Emyra Bedding untuk memaksimalkan pelayanannya.

Toko Emyra Bedding merupakan usaha bisnis di bidang dekorasi rumah yang menyediakan berbagai keperluan dekorasi rumah seperti gorden, sarung galon, sarung kulkas, taplak meja, dan sebagainya. Persediaan produk belum terkelola dengan baik, sehingga timbul beberapa permasalahan. Pelanggan sering kali membeli lebih dari satu produk. Apabila salah satu produk yang dipesan tidak tersedia, maka permintaan pelanggan akan suatu produk menjadi terhambat. Pelanggan dapat melakukan pre-order untuk produk yang tidak tersedia. Akan tetapi, proses pre-order membutuhkan waktu 7-14 hari dan pelanggan harus membayar terlebih dahulu. Hal ini berdampak pada berkurangnya kepuasan pelanggan dan bahkan dapat mengakibatkan kehilangan pelanggan.

Data transaksi penjualan belum dimanfaatkan dengan maksimal. Pengelolaan data transaksi penjualan menggunakan aplikasi Orderanku.com. Orderanku.com adalah aplikasi yang dibuat untuk memudahkan online shop mengatur dan mengelola transaksi yang diterima dari pelanggan. Data transaksi penjualan terus menumpuk dalam jumlah besar setiap harinya dan hanya disimpan menjadi data yang belum diketahui manfaatnya. Data transaksi ini dapat dimanfaatkan kembali dengan mengolah data transaksi menjadi informasi baru yang dapat membantu pihak pengambil keputusan untuk menentukan strategi persediaan produk.

Pengolahan data transaksi menjadi informasi baru yaitu menggunakan teknik data mining. Data mining adalah proses menemukan tren dan pola yang menarik dalam data dengan menggunakan satu atau beberapa algoritma (Roiger, 2017). Metode data mining yang digunakan untuk menentukan strategi persediaan produk dengan mempertimbangkan hubungan keterkaitan antar-produk yaitu association rule mining. Association rule mining digunakan untuk menemukan aturan asosiasi yang menarik 
antara suatu kombinasi item yang terdapat dalam database (Roiger, 2017). Terdapat dua algoritma dalam metode association rule mining yang digunakan yaitu algoritma Frequent Pattern Growth (FP-Growth) dan algoritma Apriori. Algoritma Apriori menghasilkan aturan asosiasi yang memenuhi ambang batas minimum support dan confidence. Algoritma FP-Growth adalah algoritma yang sangat efisien dalam pencarian frequent itemset. Algoritma Apriori dan FP-Growth telah banyak diimplementasi untuk kendali kualitas produk (Pahlevi et al., 2018), rekomendasi produk (Maulidiya \& Jananto, 2020; Riszky \& Sadikin, 2019), penataan produk (Salam et al., 2018), pola pembelian konsumen (Anggraeni et al., 2019; Bunda, 2020; Fitrianah \& Zain, 2021; Rahmawati \& Merlina, 2018; Setyorini et al., 2020; Utama et al., 2020), dan persediaan produk (Aditiya et al., 2020; Ependi \& Putra, 2019; Junaidi, 2019; Kurniawati et al., 2019).

Penelitian ini bertujuan untuk mengetahui keterkaitan produk pada Toko Emyra Bedding dengan algoritma FP-Growth dan Apriori menggunakan aplikasi RapidMiner. Dengan hal tersebut diharapkan dapat menjadi solusi dalam kelola persediaan produk sehingga dapat memaksimalkan pelayanan kepada konsumen dan memperlancar jalannya bisnis serta mempercepat proses transaksi penjualan produk tanpa adanya preorder yang membutuhkan waktu.

\section{Metode Penelitian}

Alur penelitian dilakukan secara bertahap dengan langkah-langkah yang dirancang, agar penelitian dapat berjalan dengan baik. Alur penelitian ini ditunjukkan pada Gambar 1 .

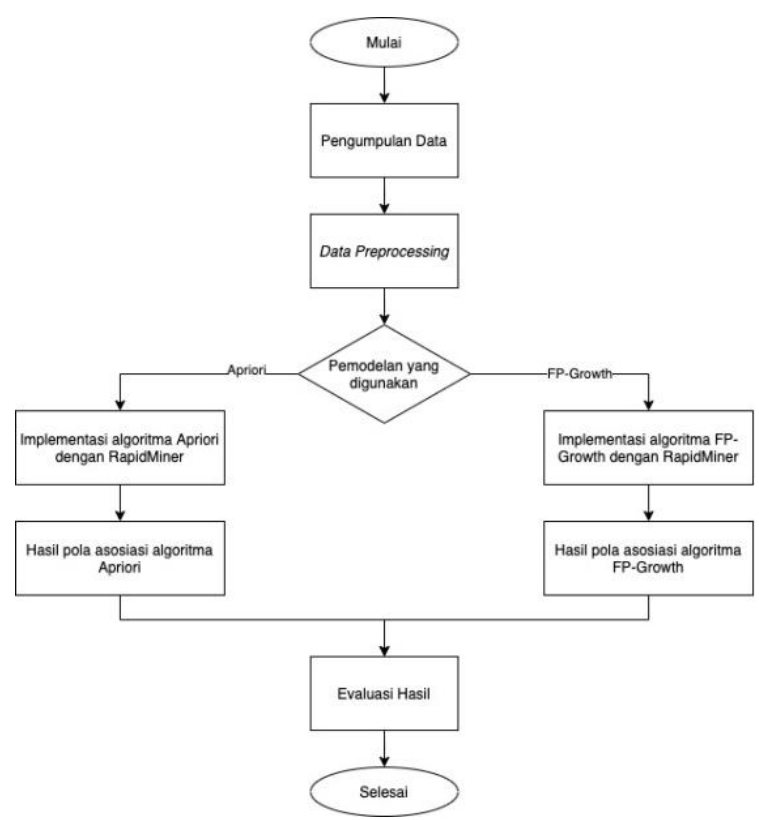

Gambar 1. Alur Penelitian

\subsection{Pengumpulan Data}

Pengumpulan data dilakukan pada Toko Emyra Bedding dengan metode pengumpulan data yaitu observasi, wawancara, dan studi pustaka. Observasi dilakukan dengan pengumpulan data informasi melalui peninjauan dan pengamatan langsung pada objek penelitian, sehingga diperoleh masalah-masalah yang ada. Wawancara dilakukan dengan tanya jawab secara langsung dengan pemilik toko, sehingga diperoleh data yang diperlukan untuk menyelesaikan masalah. Studi pustaka dilakukan dengan kajian pada penelitian-penelitian yang berkaitan dengan topik penelitian. Dataset yang digunakan sebanyak 150 data transaksi penjualan dan 17 produk.

\subsection{Data Preprocessing}

Data Preprocessing merupakan pengolahan awal data yang berupa proses menyiapkan data yang relevan dan cocok untuk digunakan dalam proses perhitungan. Pengolahan dilakukan dengan melakukan pembersihan data, pemilihan field, dan transformasi data. Pembersihan data dilakukan dengan menghilangkan data yang ganda, inkonsisten, dan kosong. Pemilihan field dilakukan untuk memilih field yang dibutuhkan dalam pemodelan. Transformasi data dilakukan dengan mengubah data menjadi binominal sehingga dapat dilakukan analisis data.

\subsection{Pemodelan}

Dalam tahapan ini dilakukan tahap pemodelan dengan menerapkan algoritma Apriori dan FPGrowth dalam pemrosesan data. Tools yang digunakan yaitu RapidMiner versi 9.9. Hasil dari tahapan ini berupa aturan asosiasi yang dihasilkan oleh algoritma Apriori dan FP-Growth. Association rules ditentukan oleh dua parameter yaitu support dan confidence. Support adalah ukuran yang menunjukkan dominasi suatu kombinasi item dalam seluruh transaksi. Confidence adalah ukuran yang menunjukkan kuatnya hubungan antar-item dalam aturan asosiasi. Persamaan (1) digunakan untuk menentukan nilai support dan Persamaan (2) digunakan untuk menentukan nilai confidence (Romadhon, 2019).

$$
\begin{aligned}
& \text { Support }(A, B)=\frac{\text { Jumlah transaksi yang mengandung } A \text { dan } B}{\text { Total Transaksi }} \\
& \text { Confidence }(A \rightarrow B)=\frac{\text { Jumlah transaksi yang mengandung } A \text { dan } B}{\text { Jumlah transaksi yang mengandung } A}
\end{aligned}
$$

\subsection{Evaluasi Hasil}

Aturan asosiasi merupakan hasil akhir yang ingin dicapai, yang bertujuan untuk mengetahui 
keterkaitan produk pada Toko Emyra Bedding. Aturan asosiasi yang dihasilkan oleh algoritma Apriori dan FP-Growth kemudian dievaluasi. Evaluasi hasil dilakukan dengan menganalisis hasil perbandingan kedua algoritma dan memberikan kesimpulan akhir.

\section{Hasil dan Pembahasan}

\subsection{Hasil Pengumpulan Data}

Penelitian ini menggunakan data transaksi penjualan pada Toko Emyra Bedding. Data tersebut diambil dari rekap transaksi pada aplikasi Orderanku.com. Data transaksi penjualan yang digunakan sebanyak 150 data. Data produk terdiri dari 17 produk. Sampel data transaksi penjualan dapat dilihat pada Tabel 1. Data produk dapat dilihat pada Tabel 2.

Tabel 1. Transaksi Penjualan

\begin{tabular}{|c|c|c|}
\hline No & Transaksi ID & Transaksi \\
\hline 1 & T001 & $\begin{array}{l}\text { Gorden Gantung, Gorden } \\
\text { Smorking Biasa, Bantal } \\
\text { Cinta }\end{array}$ \\
\hline 2 & T002 & $\begin{array}{l}\text { Gorden Smokring Rumbai } \\
\text { Tumpuk }\end{array}$ \\
\hline 3 & T003 & Set Kitchen \\
\hline 4 & T004 & $\begin{array}{l}\text { Gorden Smorking Rumbai } \\
\text { Tumpuk }\end{array}$ \\
\hline 5 & T005 & $\begin{array}{l}\text { Gorden Smokring Rumbai } \\
\text { Tumpuk }\end{array}$ \\
\hline 6 & T006 & $\begin{array}{l}\text { Gorden Smokring Rumbai } \\
\text { Tumpuk }\end{array}$ \\
\hline 7 & T007 & Gorden Smorking Biasa \\
\hline 8 & T008 & Gorden Kolong Dapur \\
\hline 9 & T009 & Gorden Kolong Dapur \\
\hline 10 & T010 & $\begin{array}{l}\text { Gorden Smokring Rumbai } \\
\text { Tumpuk }\end{array}$ \\
\hline$\cdots$ & $\cdots \cdots$ & $\cdots \cdot$ \\
\hline 146 & T146 & Gorden Gantung \\
\hline 147 & T147 & Set Kitchen \\
\hline 148 & T148 & $\begin{array}{l}\text { Gorden Gantung, Sarung } \\
\text { Bantal, Taplak Meja, } \\
\text { Gorden Kolong Dapur }\end{array}$ \\
\hline 149 & T149 & $\begin{array}{l}\text { Sarung Galon, Sarung } \\
\text { Kulkas, Sarung Magiccom }\end{array}$ \\
\hline 150 & $\mathrm{~T} 150$ & $\begin{array}{l}\text { Gorden Gantung, Sarung } \\
\text { Tissu, Gorden Smorking } \\
\text { Biasa }\end{array}$ \\
\hline
\end{tabular}

Tabel 2. Data Produk

\begin{tabular}{|c|l|l|}
\hline No & Kode Produk & \multicolumn{1}{c|}{ Nama Produk } \\
\hline 1 & B01 & Gorden Smorking Biasa \\
\hline 2 & B02 & Gorden Gantung \\
\hline 3 & B03 & Bantal Cinta \\
\hline 4 & B04 & $\begin{array}{l}\text { Gorden Smokring Rumbai } \\
\text { Tumpuk }\end{array}$ \\
\hline
\end{tabular}

\begin{tabular}{|c|l|l|}
\hline No & Kode Produk & \multicolumn{1}{c|}{ Nama Produk } \\
\hline 5 & B05 & Set Kitchen \\
\hline 6 & B06 & Gorden Kolong Dapur \\
\hline 7 & B07 & Sprei \\
\hline 8 & B08 & Sarung Tissu \\
\hline 9 & B09 & Sarung Kulkas \\
\hline 10 & B10 & Sarung Galon \\
\hline 11 & B11 & Taplak Meja \\
\hline 12 & B12 & Sarung Magiccom \\
\hline 13 & B13 & Sarung Guling \\
\hline 14 & B14 & Hanging Cloud \\
\hline 15 & B15 & Sarung Tudung Saji \\
\hline 16 & B16 & Sarung Bantal \\
\hline 17 & B17 & Sarung TV \\
\hline
\end{tabular}

\subsection{Hasil Data Preprocessing}

Data transaksi dan produk yang telah dikumpulkan kemudian dilakukan pengolahan awal. Data dibersihkan dengan memastikan tidak ada data yang ganda, inkonsisten, ataupun kosong. Kemudian dilakukan pemilihan field yang dibutuhkan yaitu Transaksi ID dan Nama Produk. Tahapan selanjutnya, dilakukan proses transformasi data. Data transaksi penjualan diubah menjadi format binominal yang berisi angka 1 dan 0. Angka 1 menunjukkan adanya transaksi untuk suatu produk, sedangkan angka 0 menunjukkan tidak adanya transaksi untuk suatu produk. Hasil data preprocessing dapat dilihat pada Tabel 3.

Tabel 3. Hasil Data Preprocessing

\begin{tabular}{|c|c|c|c|c|c|c|c|c|c|c|c|c|c|c|c|c|}
\hline & & 304 & 302 & & BO & & & & & & & & & & & \\
\hline T002 & 0 & $\begin{array}{ll}1 \\
\end{array}$ & & & 0 & & & & & & & & & & & \\
\hline & $\frac{0}{0}$ & 0 & & & $\frac{0}{0}$ & 0 & & & & & & & & & & \\
\hline & & & 0 & $\overline{0}$ & 0 & 0 & & & & & 0 & & & & & \\
\hline$\frac{\mathrm{T} 006}{\mathrm{~T} 007}$ & & $\frac{1}{0}$ & $\frac{0}{0}$ & $\frac{0}{0}$ & $\frac{0}{0}$ & $\frac{0}{0}$ & & $\frac{0}{0}$ & & & $\frac{0}{0}$ & & & & & $\frac{0}{0}$ \\
\hline & & 0 & 0 & 0 & 0 & & & 0 & & & 0 & & & & & \\
\hline$\frac{100010}{T}$ & & $\frac{0}{1}$ & & 0 & $\begin{array}{ll}0 \\
0\end{array}$ & & & $\frac{0}{0}$ & & & $\begin{array}{l}0 \\
0 \\
0\end{array}$ & & & & & 0 \\
\hline 146 & 0 & 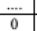 & 1 & 0 & $\overrightarrow{0}$ & $\overline{0}$ & & $\overline{0}$ & & & 菏 & & & & & 严 \\
\hline & $\frac{0}{0}$ & $\frac{1}{0}$ & & 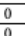 & 0 & & & & & & & & & & & \\
\hline & $\frac{0}{0}$ & $\theta$ & & & & & & & & & & & & & & 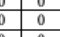 \\
\hline
\end{tabular}

\subsection{Pemodelan Algoritma Apriori dan FP- Growth dengan RapidMiner}

Dalam pemodelan algoritma Apriori dan FPGrowth dibutuhkan nilai support dan confidence. Nilai support dan confidence yang digunakan dalam pengujian algoritma Apriori dan FP-Growth dengan RapidMiner adalah:
a. Minimum Support $=0,05$
b. Minimum Confidence $=0,7$
Nilai minimum support dan minimum confidence ditentukan melalui proses pengamatan dari beberapa percobaan yang dilakukan dari data transaksi penjualan yang tersedia. Penentuan nilai- nilai ini disesuaikan untuk menghasilkan aturan asosiasi yang baik. 
Untuk melakukan pemodelan algoritma Apriori dan FP-Growth dengan RapidMiner maka perlu mendesain proses yang dibutuhkan. Desain proses algoritma Apriori dan FP-Growth ditunjukkan pada Gambar 2. Hasil data preprocessing digunakan sebagai inputan data yang akan diolah. Inputan data dikonversi dari data numerik menjadi binominal dengan operator Numerical to Binominal. Saat menguji kedua algoritma secara bersamaan, maka perlu menggunakan operator Multiply. Operator W-Apriori untuk pengujian algoritma Apriori. Operator $F P$ Growth dan Create Association Rules untuk pengujian algoritma FP-Growth.

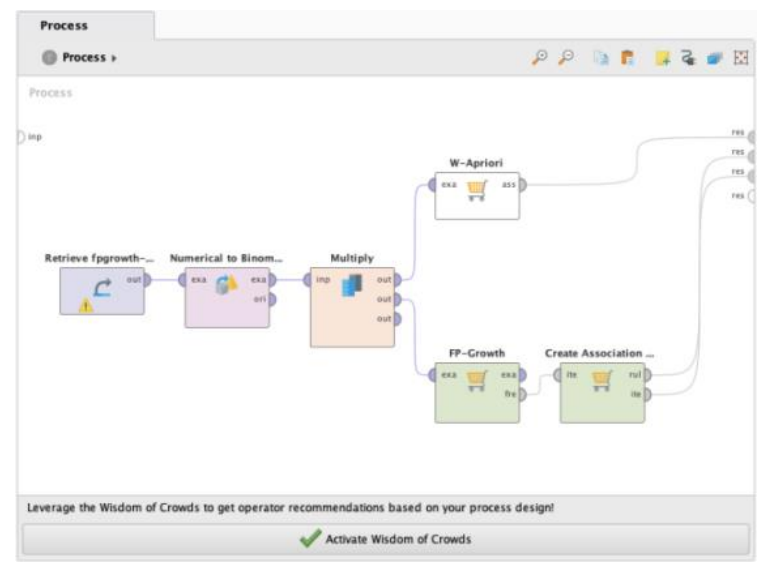

Gambar 2. Desain Proses Algoritma Apriori dan FPGrowth dengan RapidMiner

Dalam pengujian algoritma Apriori dan FPGrowth menggunakan nilai minimum support dan confidence yang telah ditentukan. Pengaturan minimum support dan confidence pada algoritma Apriori ditunjukkan pada Gambar 3. Parameter C menunjukkan minimum confidence dan parameter $\mathrm{M}$ menunjukkan minimum support.

\begin{tabular}{|c|c|c|c|}
\hline \multicolumn{2}{|c|}{$\begin{array}{l}\text { Parameters } \\
\text { W W-Apriori }\end{array}$} & $x$ & \\
\hline N & 10.0 & & (1) \\
\hline$T$ & 0.0 & & (1) \\
\hline c & 0.7 & & (1) \\
\hline D & 0.05 & & (1) \\
\hline u & 1.0 & & (1) \\
\hline M & 0.05 & & (1) \\
\hline s & -1.0 & & (i) \\
\hline
\end{tabular}

Gambar 3. Parameter Algoritma Apriori dengan RapidMiner

Pengaturan minimum support dan confidence pada algoritma FP-Growth ditunjukkan pada Gambar 4. Parameter min support pada operator FP-
Growth menunjukkan minimum support. Parameter min confidence pada operator Create Association Rules menunjukkan minimum confidence.
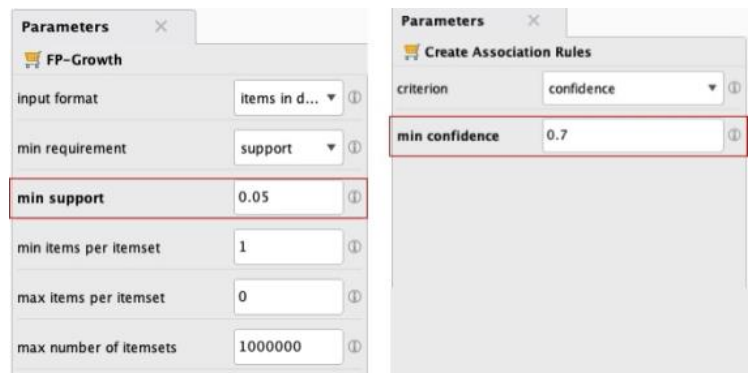

Gambar 4. Parameter Algoritma FP-Growth dengan RapidMiner

Hasil dari proses frequent item set menggunakan algoritma Apriori ditunjukkan pada Gambar 5. Jumlah aturan asosiasi yang dihasilkan sebanyak 2 aturan. Nilai confidence tertinggi yaitu 0,83 . Dua aturan asosiasi yang ditemukan dengan minimum support 0,05 yaitu sebagai berikut:

a. Aturan 1: Sarung kulkas akan terbeli bersama dengan sarung galon, dengan tingkat kepercayaan 0,83 .

b. Aturan 2: Sarung galon akan terbeli bersama dengan sarung kulkas, dengan tingkat kepercayaan 0,71 .

\section{W-Apriori}

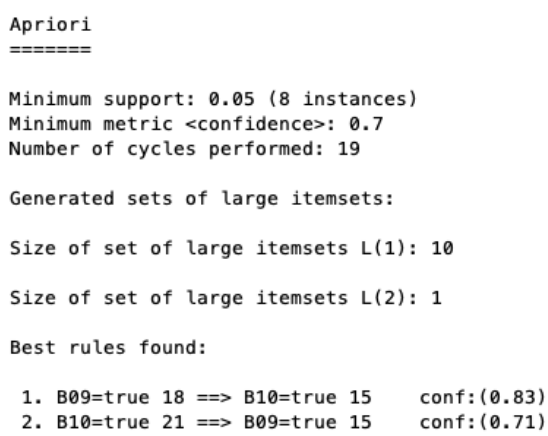

Gambar 5. Hasil Aturan Asosiasi Algoritma Apriori dengan RapidMiner

Hasil dari proses frequent item set menggunakan algoritma FP-Growth ditunjukkan pada Tabel 4. Gambar 6 menunjukkan hasil aturan asosiasi yang disajikan secara deskripsi. Sedangkan, Gambar 7 adalah grafik aturan asosiasi keterkaitan produk menggunakan RapidMiner. Aturan asosiasi yang ditemukan dengan algoritma FP-Growth sebanyak 10 aturan dan telah memetakan keterkaitan produk pada Toko Emyra Bedding. Nilai confidence tertinggi yaitu 1 . Terdapat 5 aturan asosiasi dengan nilai confidence 1. 
Tabel 4. Hasil Aturan Asosiasi Algoritma FPGrowth dengan RapidMiner

\begin{tabular}{|c|c|c|c|c|c|c|c|c|c|}
\hline \multicolumn{10}{|c|}{ n RapidMiner } \\
\hline No. & memises & Condusion & Suppon & Confidence & Laplace & Gain & p-s & ut & convicion \\
\hline 3 & $\$ 12$ & 810 & 0.047 & 0.778 & 0.987 & -0.073 & 0.038 & 5.556 & 3.870 \\
\hline 4 & 809 & 810 & 0.100 & 0.833 & 0.982 & -0.140 & 0.083 & 5.952 & 5.160 \\
\hline 5 & 809,812 & s10 & 0.033 & 0.833 & 0.994 & -0.047 & 0.028 & 5.952 & 5.160 \\
\hline 6 & 810,806 & 809 & 0.020 & 1 & 1 & -0.020 & 0.018 & 8.333 & - \\
\hline 7 & 809,806 & 810 & 0.020 & 1 & 1 & -0.020 & 0.017 & 7.143 & $\infty$ \\
\hline 8 & 809,811 & 810 & 0.013 & 1 & 1 & -0.013 & 0.011 & 7.143 & - \\
\hline , & B10, 808 & so9 & 0.013 & 1 & 1 & -0.013 & 0.012 & 8.333 & - \\
\hline 10 & 809,808 & 810 & 0.013 & 1 & 1 & -0.013 & 0.011 & 7.143 & - \\
\hline
\end{tabular}

\section{AssociationRules}

Association Rules

[B10] $\rightarrow$ [BQ9] (confidence: 0.714)

$[\mathrm{B} 10, \mathrm{B12}] \rightarrow[\mathrm{B09}]$ (confidence: 0.714)

[B12] $\rightarrow[B 10]$ (confidence: 0.778 )

[B.9] $\rightarrow$ [B10] (confldence: 0.833 )

$[B 10, B 06] \rightarrow[B 09]$ (confidence: 1.033

$[B 09, B 06] \rightarrow[B 10]$ (confidence: 1.000 )

$[B 09, B 11] \rightarrow[B 10]$ (confidence: 1.000 )

$[B 10$, BO8] $\rightarrow$ [BO9] (confidence: 1.000 )

$[\mathrm{B} 10, \mathrm{B08}] \rightarrow$
$[\mathrm{B09}, \mathrm{B08}] \rightarrow$ [B10] (confidence: 1.000 )

Gambar 6. Aturan Asosiasi Algoritma FP-Growth dalam Bentuk Deskripsi dengan RapidMiner

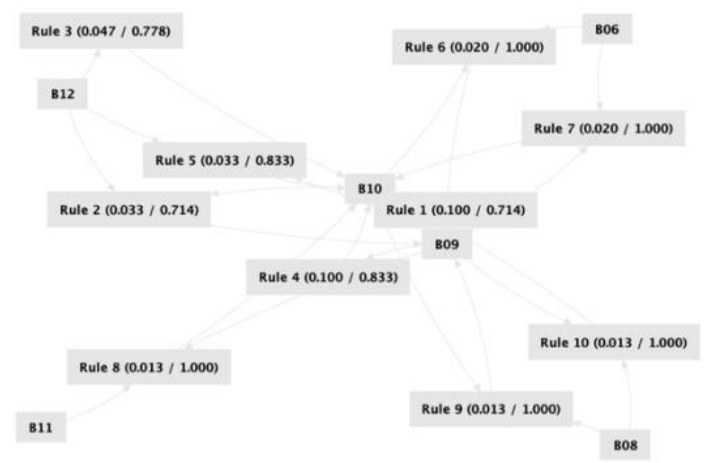

Gambar 7. Grafik Aturan Asosiasi Algoritma FPGrowth dengan RapidMiner

Berdasarkan Tabel 4, Gambar 6, dan Gambar 7 ditemukan sepuluh aturan asosiasi yang menunjukkan keterkaitan antar produk pada Toko Emyra Bedding yaitu sebagai berikut:

a. Aturan 1: Sarung galon akan terbeli bersama dengan sarung kulkas, dengan nilai confidence 0,714 dan didukung oleh 0,100 data keseluruhan.

b. Aturan 2: Sarung galon dan sarung magiccom akan terbeli bersama dengan sarung kulkas, dengan nilai confidence 0,778 dan didukung oleh 0,047 data keseluruhan.

c. Aturan 3: Sarung magiccom akan terbeli bersama dengan sarung galon, dengan nilai confidence 0,714 dan didukung oleh 0,100 data keseluruhan.

d. Aturan 4: Sarung kulkas akan terbeli bersama dengan sarung galon, dengan nilai confidence 0,833 dan didukung oleh 0,100 data keseluruhan.

e. Aturan 5: Sarung kulkas dan sarung magiccom akan terbeli bersama dengan sarung galon, dengan nilai confidence 0,833 dan didukung oleh 0,033 data keseluruhan. f. Aturan 6: Sarung galon dan gorden kolong dapur akan terbeli bersama dengan sarung kulkas, dengan nilai confidence 1,000 dan didukung oleh 0,020 data keseluruhan.

g. Aturan 7: Sarung kulkas dan gorden kolong dapur akan terbeli bersama dengan sarung galon, dengan nilai confidence 1,000 dan didukung oleh 0,020 data keseluruhan.

h. Aturan 8: Sarung kulkas dan taplak meja akan terbeli bersama dengan sarung galon, dengan nilai confidence 1,000 dan didukung oleh 0,013 data keseluruhan.

i. Aturan 9: Sarung galon dan sarung tissu akan terbeli bersama dengan sarung kulkas, dengan nilai confidence 1,000 dan didukung oleh 0,013 data keseluruhan.

j. Aturan 10: Sarung kulkas dan sarung tissu akan terbeli bersama dengan sarung galon, dengan nilai confidence 1,000 dan didukung oleh 0,013 data keseluruhan.

\subsection{Evaluasi Hasil Algoritma Apriori dan FP- Growth}

Dari hasil algoritma Apriori dan FP-Growth dapat dianalisis sebagai berikut:

a. Algoritma Apriori menghasilkan 2 aturan asosiasi sedangkan algoritma FP-Growth menghasilkan 10 aturan asosiasi dengan minimum support 0,05 dan minimum confidence 0,7 .

b. Algoritma Apriori menghasilkan nilai confidence tertinggi yaitu 0,83 sedangkan algoritma FP-Growth menghasilkan nilai confidence tertinggi yaitu 1 .

c. Aturan asosiasi yang dihasilkan oleh algoritma Apriori juga dihasilkan oleh algoritma FPGrowth, sehingga hasil algoritma Apriori sama seperti FP-Growth.

d. Tidak ada perbedaan waktu pemrosesan yang diketahui antara menggunakan algoritma Apriori dan algoritma FP-Growth, karena menggunakan tools pengujian yang sama yaitu RapidMiner dan selama proses menggunakan operator Multiply sehingga diproses secara bersamaan.

e. Dengan tools RapidMiner, aturan asosiasi yang dihasilkan oleh algoritma Apriori hanya disajikan dalam bentuk deskripsi, sedangkan algoritma FP-Growth disajikan dalam bentuk tabel data, deskripsi, dan grafik.

\section{Kesimpulan dan Saran}

Berdasarkan hasil penelitian dan pembahasan, dapat disimpulkan bahwa baik algoritma Apriori dan FP-Growth dapat digunakan untuk menentukan aturan asosiasi yang dapat mengetahui keterkaitan produk pada Toko Emyra Bedding. Aturan asosiasi yang dihasilkan oleh algoritma Apriori juga 
dihasilkan oleh algoritma FP-Growth, yaitu algoritma Apriori menghasilkan 2 aturan asosiasi dan algoritma FP-Growth menghasilkan 10 aturan asosiasi dengan minimum support 0,05 dan minimum confidence 0,7. Algoritma Apriori menghasilkan nilai confidence tertinggi yaitu 0,83 sedangkan algoritma FP-Growth menghasilkan nilai confidence tertinggi yaitu 1. Pola hubungan yang dihasilkan, dapat membantu Toko Emyra Bedding untuk memantau stok barang yang sering dibeli oleh pelanggan sehingga tidak akan terjadi kelangkaan pasokan.

Penelitian lanjutan dari penelitian ini yaitu melakukan pemodelan menggunakan tools selain RapidMiner sehingga dapat menjadi pembanding. Selain itu, melakukan penelitian menggunakan lebih banyak data transaksi penjualan, karena pada penelitian ini hanya menggunakan 150 data.

\section{Ucapan Terima Kasih}

Penulis ingin mengucapkan terima kasih kepada Universitas Amikom Yogyakarta yang telah memberikan dukungan untuk penelitian ini.

\section{Daftar Pustaka:}

Aditiya, R., Defit, S., \& Nurcahyo, G. W. (2020). Prediksi Tingkat Ketersediaan Stock Sembako Menggunakan Algoritma FP-Growth dalam Meningkatkan Penjualan. Jurnal Informatika Ekonomi Bisnis, 2(3), 67-73.

Anggraeni, S., Iha, M. A., Erawati, W., \& Khairunnas, S. (2019). Analysis of Sales by Using Apriori and FP-Growth at PT. Panca Putra Solusindo. Riset Dan E-Jurnal Manajemen Informatika Komputer, 3(2), 4147.

Bunda, Y. P. (2020). Algoritma FP-Growth untuk Menganalisa Pola Pembelian Oleh-Oleh (Studi Kasus di Pusat Oleh-Oleh Ummi Aufa Hakim). Riau Journal of Computer Science, 06(01), 34-44.

Ependi, U., \& Putra, A. (2019). Solusi Prediksi Persediaan Barang dengan Menggunakan Algoritma Apriori (Studi Kasus: Regional Part Depo Auto 2000 Palembang). JEPIN (Jurnal Edukasi Dan Penelitian Informatika), 5(2), 139-145.

Fitrianah, D., \& Zain, S. Y. (2021). Analysis of Consumer Purchase Patterns on Handphone Accessories Sales Using FP-Growth Algorithm. Proceedings of the International Conference on Engineering, Technologyand Social Science (ICONETOS 2020), 149-158.
Junaidi, A. (2019). Implementasi Algoritma Apriori dan FP-GrowthUntuk Menentukan Persediaan Barang. Jurnal SISFOKOM, 08(01), 61-67.

Kurniawati, L., Kusuma, A. E., \& Dewansyah, B. (2019). Implementasi Algoritma Apriori untuk Menentukan Persediaan Spare Part Compressor. CESS (Journal of Computer Engineering System and Science), 4(1), 6-10.

Maulidiya, H., \& Jananto, A. (2020). Asosiasi Data Mining Menggunakan Algoritma Apriori dan FP-Growth Sebagai Dasar Pertimbangan Penentuan Paket Sembako. Proceeding SENDIU, 36-42.

Pahlevi, O., Sugandi, A., \& Sintawati, I. D. (2018). Penerapan Algoritma Apriori Dalam Pengendalian Kualitas Produk. Jurnal \& Penelitian Teknik Informatika, 3(1), 272-278.

Rahmawati, F., \& Merlina, N. (2018). Metode Data Mining Terhadap Data Penjualan Sparepart Mesin Fotocopy Menggunakan Algoritma Apriori. Jurnal Penelitian Ilmu Komputer, System Embedded \& Logic, 6(1), 9-20.

Riszky, A. R., \& Sadikin, M. (2019). Data Mining Menggunakan Algoritma Apriori untuk Rekomendasi Produk bagi Pelanggan. Jurnal Teknologi Dan Sistem Komputer, 7(3), 103108.

Roiger, R. J. (2017). Data Mining A Tutorial-Based Primer (2nd Edition). Chapman and Hall/CRC.

Romadhon, W. (2019). Data Mining Dalam Menentukan Cross Selling Produk Citramart Menggunakan Algoritma FP-Growth.

Salam, A., Zeniarja, J., Wicaksono, W., \& Kharisma, L. (2018). Pencarian Pola Asosiasi untuk Penataan Barang dengan Menggunakan Perbandingan Algoritma Apriori dan FPGrowth (Studi Kasus Distro Epo Store Pemalang). Jurnal DINAMIK, 23(2), 57-65.

Setyorini, S. G., Mustakim, Adhiva, J., \& Putri, S. A. (2020). Penerapan Algoritma FP-Growth dalam Penentuan Pola Pembelian Konsumen. Seminar Nasional Teknologi Informasi, Komunikasi Dan Industri (SNTIKI), 180-186.

Utama, K. M. R. A. U., Umar, R., \& Yudhana, A. (2020). Penerapan Algoritma FP-Growth untuk Penentuan Pola Pembelian Transaksi Penjualan pada Toko KGS Rizky Motor. Jurnal DINAMIK, 25(1), 20-28. 